BACTERIAL RESISTANCE TO ISONIAZID AND “MARSILID" IN TREATMENT OF PULMONARY TUBERCULOSIS

\section{RESULTS OF TRIALS}

\section{BY}

\author{
C. M. OGILVIE, M.D., M.R.C.P. \\ Medical First Assistant, the London Hospital
}

Bacteriological and clinical resistance appears in a high proportion of patients with pulmonary tuberculosis treated with isoniazid alone (Medical Research Council, 1952 ; Joiner et al., 1952). The value of daily injections of streptomycin in preventing resistance to isoniazid has been amply demonstrated (Medical Research Council, 1953a), but streptomycin given in doses of $1 \mathrm{~g}$. twice weekly is less effective for this purpose (United States Public Health Service, 1953 ; Medical Research Council, 1953b). The incidence of resistance to "marsilid" (1isonicotinyl-2-isopropyl hydrazine) is not known, since this drug is not yet available for general use. Nash and Grosfeld (1952) recovered resistant strains from three of four patients treated with marsilid for six weeks. . Robitzek et al. (1953), on the other hand, found resistant strains in only one of 14 patients treated for an average period of 112 days.

The purpose of the present paper is to report the results of sputum-sensitivity tests carried out before, during, and after treatment with isoniazid and marsilid (alone, and in combination with streptomycin).

\section{Laboratory Methods}

1. Isoniazid Sensitivity Tests.-The specimen of sputum under investigation was first concentrated and inoculated on to a plain Löwenstein-Jensen slope. Löwenstein-Jensen slopes containing concentrations of $0.2,1,5$, and $50 \mu \mathrm{g}$. of isoniazid per $\mathrm{ml}$. and a plain control were then inoculated from the resulting culture by the following method. A platinum loop (slightly opened and therefore incapable of taking up a loopful of fluid) was rubbed over some 2 square $\mathrm{cm}$. or more of medium until the growth was broken up, large masses being pushed aside. After resterilization in boiling water and flame, the loop was then rubbed over the clear area before the inoculation of each tube. The slopes were incubated at $37^{\circ} \mathrm{C}$. for 21 days. Resistance was recorded when there was growth on any of the slopes containing isoniazid, but a growth of fewer than 10 colonies on the 0.2- $\mu \mathrm{g}$. slope was disregarded. (A growth of fewer than 10 colonies in the higher concentrations occurred in five cases; these are discussed below.) Sensitivity was recorded when no growth occurred on any of the isoniazid slopes after 21 days' incubation, provided that there was then a free growth in the control.

2. Marsilid Sensitivity.-The same technique was used with Löwenstein-Jensen slopes containing marsilid instead of isoniazid. Resistance was recorded when growth occurred on the slopes containing 5 or $50 \mu \mathrm{g}$. per ml. (See discussion.)

3. Streptomycin sensitivity was tested by the above technique, using Löwenstein-Jensen slopes containing 3 and $30 \mu \mathrm{g}$. of streptomycin per ml. and a plain control. Resistance was recorded when there was growth on either of the drug slopes, fewer than 10 colonies on the $3-\mu \mathrm{g}$. slope being disregarded.

\section{Laboratory Results}

Using the method described above, more than 500 tests for isoniazid sensitivity have now been carried out at the London Hospital. Of 125 cultures tested for isoniazid sensitivity before treatment with this drug, 118 were sensitive to a concentration of $0.2 \mu \mathrm{g}$. per $\mathrm{ml}$. Strains resistant to $0.2 \mu \mathrm{g}$. per $\mathrm{ml}$. (but sensitive to higher concentrations) were recovered from seven patients $(5.6 \%)$, but in each case growth was less than that on the control; four have subsequently yielded strains inhibited in the $0.2 \mu \mathrm{g}$. medium despite two to three months' treatment with isoniazid. This incidence of "doubtfully" resistant strains in pre-treatment cultures accords closely with the findings of the Medical Research Council (1953a), who reported growth in the $0.2-\mu \mathrm{g}$. medium in 10 of $180(5.5 \%)$ pre-treatment cultures.

Steenken and Wolinsky (1952) have shown that the minimal concentration of marsilid required to inhibit the H37Rv strain of Mycobacterium tuberculosis (1.6$3.1 \mu \mathrm{g}$. per ml.) is about sixty times greater than the equivalent concentration of isoniazid $(0.02-0.05 \mu \mathrm{g}$. per $\mathrm{ml}$.), but considerable variation occurred according to the type of medium used. We have found that the H37Rv strain will grow on Löwenstein-Jensen slopes containing marsilid in concentrations of 0.2 and $1 \mu \mathrm{g}$. per ml., but growth is inhibited on the slopes containing 5 and $50 \mu \mathrm{g}$. per $\mathrm{ml}$. Cultures from 25 patients have been tested simultaneously for marsilid and isoniazid sensitivity after treatment with one of these drugs. Eleven of these were resistant to isoniazid-four after treatment with marsilid and seven after treatment with isoniazid. The cultures resistant to $0.2 \mu \mathrm{g}$. of isoniazid were also resistant to $5 \mu \mathrm{g}$. of marsilid, and those resistant to $1 \mu \mathrm{g}$. (or higher concentrations) of isoniazid were also resistant to $50 \mu \mathrm{g}$. of marsilid. The 13 cultures sensitive to $0.2 \mu \mathrm{g}$. of isoniazid were also sensitive to $5 \mu \mathrm{g}$. of marsilid. We have therefore concluded that there is cross-resistance between marsilid and isoniazid and that neither of these drugs is likely to have a significant inhibitory effect upon strains resistant to the other. For practical purposes, therefore, the standard isoniazid media should be satisfactory for the testing of marsilid sensitivity.

Of 117 cultures tested for streptomycin sensitivity before treatment with this drug, 114 were sensitive to $3 \mu \mathrm{g}$. per $\mathrm{ml}$. Strains of bacilli resistant to $3 \mu \mathrm{g}$. but sensitive to $30 \mu \mathrm{g}$. Were recovered from the other three patients. Further cultures were obtained from two of these patients after streptomycin had been given for three months, and both were then sensitive to $3 \mu \mathrm{g}$. per ml. The Medical Research Council (1953a) found that 4 out of 279 pre-treatment cultures were resistant to streptomycin.

\section{Clinical Trial}

The clinical and bacteriological manifestations of drug resistance may be so dramatic that the inadequacy of certain regimes of chemotherapy can be disclosed in quite small groups of patients. This was well shown by Joiner et al. (1952) in their trials with isoniazid alone and in combination with streptomycin.

At the London Hospital, strong clinical evidence of isoniazid resistance was found in a large proportion of patients treated with this drug alone between March and June, 1952 (Bartley, 1952). It was then decided that large groups of patients should not be committed to any one regime of chemotherapy until the incidence of bacterial resistance with that particular regime had been assessed in a small "pilot" group. Trials on a larger scale could then be undertaken in those groups showing a low incidence of resistance. With this object in view, four groups of patients with pulmonary tuberculosis have now been treated at the 
London Hospital according to the following regimes of chemotherapy:

Group I (10 patients): isoniazid, $300 \mathrm{mg}$. daily, + streptomycin, 1 g. twice weekly.

Group II ( 9 patients) : marsilid, $300 \mathrm{mg}$. daily.

Group III (17 patients): marsilid, $300 \mathrm{mg}$. daily, + streptomycin, 1 g. three times weekly.

Group IV (10 patients): isoniazid, $300 \mathrm{mg}$. daily, + streptomycin, $1 \mathrm{~g}$. three times weekly.

The criteria required for admission to one of these four groups were: (1) that the patient should not previously have had isoniazid or marsilid; (2) that tubercle bacilli should have been recovered from a specimen of sputum collected within one week of the start of treatment; and (3) that the pre-treatment culture should not grow in a concentration of $0.2 \mu \mathrm{g}$. of isoniazid per $\mathrm{ml}$. or $3 \mu \mathrm{g}$. of streptomycin per ml.

All cases of pulmonary tuberculosis regarded as suitable for chemotherapy and also fulfilling the above criteria were allotted to one of the treatment groups according to the following scheme : from August to December, 1952, patients were allotted alternately to Groups I and II. In December, 1952, it was realized that a high incidence of resistance was occurring in Groups I and II. Both these groups were therefore withdrawn, and from January to October, 1953, patients were allotted alternately to Groups III and IV. More recently Group IV proved unsatisfactory and was also withdrawn, subsequent cases being allotted to Group III.

In each group the prescribed regime of chemotherapy was given for 100 days. Treatment was interrupted only if withdrawal of a drug was necessary because of toxic reactions, but in no case was a drug withheld for more than three days. Bacterial sensitivity to isoniazid (or marsilid) and to streptomycin was tested immediately before and after the course of treatment and also at monthly intervals during treatment. The final sensitivity of the organisms after treatment was confirmed in at least two separate specimens of sputum.

The results of these isoniazid (and marsilid) sensitivity tests are shown in Table I. Streptomycin-resistant strains were not recovered from patients in any of the four treatment groups.

TABLE I.-Development of Resistance to Isoniazid (and Marsilid) in Four Treatment Groups

\begin{tabular}{|c|c|c|c|c|c|c|c|c|c|}
\hline \multirow[t]{2}{*}{ Group } & \multirow{2}{*}{$\begin{array}{l}\text { Total } \\
\text { No. of } \\
\text { Cases }\end{array}$} & \multicolumn{2}{|c|}{ 1. Month } & \multicolumn{2}{|c|}{2 Months } & \multicolumn{2}{|c|}{3 Months } & \multicolumn{2}{|c|}{$\begin{array}{l}\text { After } \\
\text { Treatment } \\
\text { (100 Days) }\end{array}$} \\
\hline & & $\mathbf{S}$ & $\mathbf{R}$ & $\mathbf{S}$ & $\mathbf{R}$ & $\mathbf{S}$ & $\mathbf{R}$ & $\mathbf{S}$ & $\mathbf{R}$ \\
\hline $\begin{array}{l}\text { II } \\
\text { III }\end{array}$ & $\begin{array}{r}10 \\
9 \\
17 \\
10\end{array}$ & $\begin{array}{r}10 \\
6 \\
13 \\
6\end{array}$ & $\begin{array}{l}\mathbf{0} \\
\mathbf{0} \\
\mathbf{0} \\
\mathbf{0}\end{array}$ & $\begin{array}{r}8 \\
4 \\
12 \\
6\end{array}$ & $\begin{array}{l}\mathbf{0} \\
\mathbf{3} \\
\mathbf{0} \\
\mathbf{0}\end{array}$ & $\begin{array}{l}7 \\
0 \\
9 \\
2\end{array}$ & $\begin{array}{l}0 \\
5 \\
0 \\
2\end{array}$ & $\begin{array}{l}1 \\
0 \\
7 \\
1\end{array}$ & $\begin{array}{l}3 \\
6 \\
0 \\
4\end{array}$ \\
\hline
\end{tabular}

The number of positive cultures sensitive (S) and the number resistant (R) to isoniazid (and marsilid) are shown at each stage of treatment.

\section{Comment}

It has already been stated that the object of this trial was to determine the incidence of bacterial resistance in small "pilot" treatment groups with a view to large-scale trials of those groups showing a low incidence of resistance. The number of cases in each treatment group is too small to justify any comment upon the relative effect of the different regimes upon clinical progress. The following observations may, however, be made:

(1) Bacterial resistance to marsilid (Group II) develops in a high proportion of cases within two to three months, but the emergence of resistant strains can be postponed by combination with streptomycin (Group III). In this respect, marsilid behaves in similar fashion to isoniazid and should in no circumstances be given alone.

(2) Although bacterial resistance to isoniazid was delayed by combination with $1 \mathrm{~g}$. of streptomycin twice weekly (Group I) or thrice weekly (Group IV), a high incidence of isoniazid-resistant strains were found in the fourth month of treatment in both these groups. Of nine cultures available in the fourth month of treatment, five were resistant to $50 \mu \mathrm{g}$. of isoniazid and two to $1 \mu \mathrm{g}$. A more extensive trial of these two treatment groups (Groups I and IV) is not considered advisable. Streptomycinresistant strains were not recovered from cases in either of these groups even when isoniazid resistance had emerged. (It should be noted, however, that in no case was streptomycin given for more than four to five weeks after the appearance of isoniazidresistant strains.)

(3) As already stated, cases were allotted alternately to Group IV and Group III. These two groups form part of another trial in which isoniazid and marsilid are being compared; the results of this trial will be published at a later date. Although the figures are small, it is of interest that, in the isoniazid group, resistant strains were recovered from four of the five cultures available in the fourth month, whereas in the marsilid group all of the seven cultures available in the fourth month were sensitive. In order to determine whether differences in the type of disease had significantly affected the incidence of resistance in the two groups, the pre-treatment status of the cases with cultures available for sensitivity tests after 100 days' treatment have been compared. Table II shows that there is no gross disparity between the two groups in regard to the duration, type and extent of the disease. The Medical Research Council (1952) found that isoniazid-resistance developed equally often in each of the three disease groups studied, but a higher incidence of resistance was noted among those patients acutely ill at the start of treatment. This latter factor is unlikely to have affected the results in the present study: at the start of treatment none of the patients was acutely ill and the average level of the blood sedimentation rate was actually higher in the marsilid than in the isoniazid group.

TABLE II.-Clinical Condition of Patients in Groups III and IV Before Treatment. A Comparison of the Pre-treatment Condition of Patients Yielding Positive Cultures After 100 Days' Treatment with Marsilid and Isoniazid

\begin{tabular}{|c|c|c|}
\hline & Group III & Group IV \\
\hline 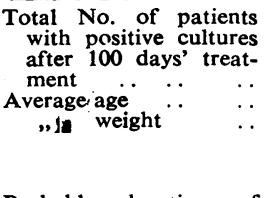 & $\begin{array}{c}7 \\
40 \text { years } \\
117 \mathrm{lb}(52 \mathrm{~kg} .) \\
\text { (average of } 18 \cdot \mathrm{lb} \text {. } \\
(8 \cdot 2 \mathrm{~kg} .) \text { below normal } \\
\text { weight) }\end{array}$ & $\begin{array}{c}5 \\
45 \text { years } \\
132 \mathrm{lb} \text {. ( } 59.9 \mathrm{~kg} .) \\
\text { (average of } 14 \mathrm{lb} \text {. } \\
\text { (6.35 kg.) below normal } \\
\text { weight) }\end{array}$ \\
\hline $\begin{array}{l}\text { Probable duration of } \\
\text { disease: } \\
\text { Less than } 6 \text { months } \\
\text { More " } 12 \\
\text { Previous" treatment in }\end{array}$ & ${ }_{2}^{5}$ cases & $\begin{array}{l}4 \text { cases } \\
1 \text { case }\end{array}$ \\
\hline 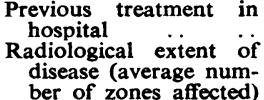 & 2 & 1 \\
\hline 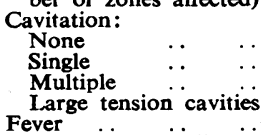 & $\begin{array}{l}1 \\
2 \\
4 \\
4 \\
2 \text { cases }\end{array}$ & $\begin{array}{l}1 \\
1 \\
3 \\
3 \\
2 \text { cases }\end{array}$ \\
\hline $\begin{array}{c}\text { Average blood sedimen- } \\
\text { tation rate }\end{array}$ & & \\
\hline
\end{tabular}

\section{Reversion to Isoniazid Sensitivity}

In the Medical Research Council (1953c) trials it was found that of 28 patients with resistant strains at the end of three months' treatment with isoniazid, only one yielded a sensitive strain and two others doubtfully resistant strains three months after the drug was withdrawn. The Medical Research Council Report concluded that over a threemonths' period there was no evidence of any general reversion of isoniazid-resistant strains either to a lower level of resistance or to sensitivity.

On the other hand, there is in vitro evidence (Pansy et al., 1952 ; Barnett et al., 1953a) that isoniazid-resistant strains may revert to sensitivity, and this has also been noted in patients after isoniazid treatment is stopped (Nitti, 1952 . Knox, 1953 ; Nigoghossian, 1953).

At the London Hospital 21 patients from whom resistant bacilli were recovered after treatment with isoniazid or marsilid have been observed for periods of four to twelve months after the cessation of treatment. In each case resistance was confirmed in at least two separate specimens 
of sputum. The frequency of subsequent tests for sensitivity depended to some extent upon the availability of suitable bacterial cultures; tests were also made more often whenever a change in the level of resistance had been detected. Table III shows that 9 of these 21 resistant cases

TABLE III.-Changes in Level of Isoniazid Resistance After Cessation of Treatment. (Degree of Resistance is expressed in $\mu \mathrm{g}$. per $\mathrm{ml}$. of Isoniazid)

\begin{tabular}{|c|c|c|c|c|c|c|c|c|c|c|c|c|c|}
\hline \multirow{2}{*}{$\begin{array}{l}\text { Case } \\
\text { No. }\end{array}$} & \multirow{2}{*}{$\begin{array}{l}\text { At End } \\
\text { of Treat- } \\
\text { ment }\end{array}$} & \multicolumn{12}{|c|}{ Months After Treatment Stopped } \\
\hline & & 1 & 2 & 3 & 4 & 5 & 6 & 7 & 8 & 9 & 10 & 11 & 12 \\
\hline $\begin{array}{r}1 \\
2 \\
3 \\
4 \\
5 \\
6 \\
7 \\
8 \\
9 \\
10 \\
11 \\
12 \\
13 \\
14 \\
15 \\
16 \\
17 \\
18 \\
19 \\
20 \\
21\end{array}$ & $\begin{array}{r}50 \\
1 \\
50 \\
5 \\
5 \\
50 \\
50 \\
50 \\
50 \\
50 \\
5 \\
50 \\
50 \\
1 \\
50 \\
5 \\
50 \\
50 \\
1 \\
5 \\
50\end{array}$ & $\mathbf{S}$ & $\begin{array}{r}1 \\
50\end{array}$ & $\begin{array}{r}1 \\
1 \\
1 \\
50\end{array}$ & $\begin{array}{r}1 \\
\\
5 \\
50 \\
50 \\
1 \\
S \\
S \\
0 \cdot 2 \\
S \\
S \\
S \\
S\end{array}$ & $\begin{array}{r}50 \\
1 \\
5 \\
50 \\
5 \\
50 \\
1 \\
\mathrm{C} \\
\\
\mathrm{S} \\
50\end{array}$ & $\begin{array}{c}1 \\
1 \\
1 \\
5 \\
50 \\
\mathrm{~S} \\
\mathrm{~S} \\
\mathrm{~S}\end{array}$ & $\begin{array}{r}5 \\
50 \\
\\
1 \\
50 \\
\mathrm{~S} \\
\\
\mathbf{S} \\
\mathbf{S} \\
\mathbf{S} \\
\mathrm{C} \\
1\end{array}$ & $\begin{array}{r}1 \\
50 \\
1 \\
1 \\
50\end{array}$ & $\mathbf{S}$ & $\begin{array}{r}50 \\
.1 \\
1 \\
50 \\
\mathrm{C}\end{array}$ & $\begin{array}{l}\mathrm{C} \\
\mathrm{S}\end{array}$ & $\stackrel{\mathbf{S}}{\mathbf{S}}$ \\
\hline
\end{tabular}

$S=$ Sensitive to a concentration of $0 \cdot 2 \mu \mathrm{g}$. per ml. of isoniazid.
$C=$ Growth of fewer than 10 colonies in two or more of the four drug concentrations.

(44.4\%) have now yielded strains sensitive to $0.2 \mu \mathrm{g}$. of isoniazid per $\mathrm{ml}$. (In seven of these, examination of two or more consecutive specimens of sputum has failed to reveal resistant organisms.) Another seven patients have yielded strains of a reduced level of resistance, and in only five cases has the degree of resistance remained unchanged. Six of the nine patients showing reversion to sensitivity yielded their first sensitive strains within four months of the cessation of treatment. In one case (No. 17) sensitive strains were recovered in the first month, and two patients (Cases 8 and 7), who had yielded highly resistant strains until the tenth month, produced sensitive strains in the eleventh and twelfth months respectively. Three patients (Cases 12, 17 , and 18) produced strains of varying sensitivity before a consecutive series of sensitive cultures was obtained.

Since resistance to isoniazid can now be prevented in most cases by combination of the drug with streptomycin, a clinical evaluation of the factors affecting reversion to sensitivity must necessarily be retrospective and involve comparatively small numbers of cases. In the present study, four possible factors have been considered :

(1) Original Level of Resistance.-The rate of reversion is apparently unrelated to the original level of resistance. Cultures from one patient (Case 2) have remained consistently resistant to a concentration of $1 \mu \mathrm{g}$. of isoniazid per $\mathrm{ml}$. for ten months, and cultures from another three patients (Cases 4, 5, and 11), which were resistant to $5 \mu \mathrm{g}$. per $\mathrm{ml}$. at the end of treatment, were still resistant to $1 \mu \mathrm{g}$. per $\mathrm{ml}$. more than nine months later. On the other hand, cultures from eight patients which were originally resistant to $50 \mu \mathrm{g}$. per $\mathrm{ml}$. have now become sensitive to $0.2 \mu \mathrm{g}$. per ml., three of these within four months of the cessation of treatment.

(2) Form of Administration of Drugs.-Reversion to sensitivity occurred whether the patients were originally treated with marsilid (three reversions) or isoniazid (six reversions). Four patients rendered resistant to isoniazid when it was combined with either P.A.S. (three cases) or streptomycin, $1 \mathrm{~g}$. twice weekly (one case), all reverted to sensitivity. (The remainder of the 21 patients in this study had received either marsilid or isoniazid alone.)

(3) Duration of Drug Treatment.-The five patients in whom the degree of resistance remained unchanged had all received more than 120 days' treatment (average, 157 days) with either isoniazid or marsilid, $200-300 \mathrm{mg}$. daily. Seven of the nine patients showing reversion to sensitivity had received less than 100 days' treatment (average, 83 days) with isoniazid or marsilid in the same dosage. It is of interest that the other two patients (dura- tion of treatment, 125 and 128 days respectively) did not yield sensitive strains until more than eleven months after the cessation of treatment. (In order to show these points more clearly, the cases recorded in Table III have been numbered according to the duration of isoniazid treatment: Case 1 had received the longest course, and Case 21 the shortest course.)

(4) Type of Disease.- If the 11 patients who remained resistant for more than six months after the cessation of treatment (Group R) are compared with the six who yielded sensitive strains within this period (Group S), certain interesting differences are revealed. In Group $R$ the disease had been diagnosed for more than two years and had failed to respond to previous treatment in hospital in 10 of the 11 cases. Only one patient in Group $S$ had been diagnosed for more than two years and three had received previous hospital treatment. Four or more lung zones were involved in all but three patients in Group $\mathbf{R}$ and in only two patients in Group S. Large tension cavities were present in four Group $R$ patients and in none of the Group $S$ patients. Nine of the 11 patients in Group $R$ had more than one cavity as compared with three of the six Group $S$ cases. Differences in the general condition of the patients and the activity of the disease in the two groups at the start of drug treatment were not conspicuous, and all were sputum-positive on direct microscopical examination. The progress of the patients in these two groups may well reflect differences in their status at the start of treatment. All the six patients in Group $S$ have undergone thoracoplasty, five have shown clinical improvement, and three have been discharged from hospital. Four were sputum-negative on direct microscopical examination, but a second course of isoniazid had been given to three of these after reversion to sensitivity was noted. In Group $R 4$ of the 11 patients have been fit to undergo surgical treatment, four are sputum-negative on direct examination, and only one has been discharged from hospital. Six of the patients still have large cavities and a heavily positive sputum; four have deteriorated clinically and one has died.

It is clear that with such small numbers of cases there must be an appreciable overlap in the operation of the factors which have been considered. For instance, longer courses of isoniazid or marsilid treatment were advised for some of the more advanced cases, and it is not possible to be certain which of these two factors may have delayed reversion to sensitivity. It is apparent, however, that differences between the cases reverting to sensitivity and those remaining resistant do exist and that reversion may be a predictable rather than a fortuitous phenomenon.

\section{Significance of Bacteriological Resistance and Reversion to Sensitivity}

It is known that clinical relapse may accompany the emergence of resistant strains during isoniazid therapy. This was certainly noted in a high proportion of cases treated with isoniazid alone at the London Hospital in the spring of 1952 (Bartley, 1952) and in cases treated with marsilid alone in the autumn of the same year (Ogilvie, 1953). This relapse was usually associated with a recurrence of symptoms, a transient fever, an increase in the amount of sputum (sometimes with reversion from negative to positive), and the cessation of radiological improvement. Loss of weight was not a conspicuous feature ; in fact, a number of the patients on marsilid continued to gain weight while deteriorating in other respects. When isoniazid is combined with streptomycin or P.A.S. the emergence of isoniazidresistant strains is, in our experience, only rarely accompanied by a detectable clinical relapse. As noted previously, the bacilli may remain sensitive to streptomycin (given two or three times weekly) for some weeks after acquiring resistance to isoniazid, and the former drug may thus continue to control the infection.

It is, on the other hand, quite a common experience to find that a clinical response to isoniazid alone may continue after resistant strains have first been detected in the laboratory. This may imply a combined infection by sensitive and resistant organisms, a possibility which is supported ty our own findings. It has already been stated that in three of our cases (Nos. 12, 17, and 18 in Table III) there was a variation in the sensitivity of cultures grown from different specimens of sputum before the appearance of a consecutive series of sensitive cultures. In two of these 
three cases (Cases A and B in Table IV) and in two other cases not included in the present series (Cases $C$ and $D$ ), a simultaneous variation in sensitivity to isoniazid and streptomycin has been found (see Table IV). Our findings in five other cases (including Cases 7, 8, 13, and 19 in Table III) suggest that a single specimen of sputum may contain a

TABLE IV.-Simultaneous Variation in Isoniazid and Streptomycin Sensitivity

\begin{tabular}{|c|c|c|c|}
\hline Case & Date & Sensitivity to Streptomycin & Sensitivity to Isoniazid \\
\hline $\mathbf{A}$ & $\begin{array}{r}26 / 3 / 53 \\
6 / 5 / 53 \\
4 / 6 / 53 \\
17 / 7 / 53 \\
10 / 8 / 53\end{array}$ & $\begin{array}{l}\text { Growth in } 3 \mu \mathrm{g} . \text { per } \mathrm{ml} . \\
\mathrm{S} \\
\text { Growth in } 3 \mu \mathrm{g} . \text { per } \mathrm{ml} . \\
\mathbf{S} \\
\mathbf{S}\end{array}$ & $\begin{array}{l}\text { Growth in } 50 \mu \mathrm{g} . \text { per } \mathrm{ml} \text {. } \\
\mathrm{S} \\
\text { Growth in } 50 \mu \mathrm{g} . \text { per } \mathrm{ml} \text {. } \\
\mathrm{S} \\
\mathrm{S}\end{array}$ \\
\hline B & $\begin{array}{r}11 / 2 / 53 \\
8 / 5 / 53 \\
15 / 7 / 53\end{array}$ & $\begin{array}{l}\text { Growth in } 30 \mu \mathrm{g} . \text { per } \mathrm{ml} . \\
\mathrm{S}\end{array}$ & $\begin{array}{l}\text { Growth in } 50 \mu \mathrm{g} . \text { per } \mathrm{ml} \text {. } \\
\mathrm{S} \\
\mathrm{S}\end{array}$ \\
\hline $\mathrm{C}$ & $\begin{array}{l}18 / 8 / 53 \\
14 / 9 / 53\end{array}$ & Growth in $3 \mu \mathrm{g}$. per $\mathrm{ml}$. & Growth in $0.2 \mu \mathrm{g}$. per $\mathrm{ml}$. \\
\hline D & $\begin{array}{l}13 / 4 / 53 \\
15 / 8 / 53\end{array}$ & $\begin{array}{l}\text { Growth in } 3 \mu \mathrm{g} . \text { per } \mathrm{ml} . \\
\mathrm{S}\end{array}$ & Growth in $0.2 \mu \mathrm{g}$. per $\mathrm{ml}$. \\
\hline
\end{tabular}

$\mathrm{S}=$ Sensitive to $3 \mu \mathrm{g}$. of streptomycin per $\mathrm{ml}$. or $0.2 \mu \mathrm{g}$. of isoniazid per $\mathrm{ml}$.

mixture of sensitive and resistant organisms. In each of these cases a small number of colonies of tubercle bacilli were observed in two or more of the four drug concentrations, while a profuse growth occurred on the control medium. (In the Medical Research Council Trials a growth of fewer than 20 colonies on any of the drug media was disregarded. The possible significance of this phenomenon in patients who have previously yielded resistant strains is discussed in paragraph 3 below.)

Certain tentative conclusions may be drawn from these observations :

(1) The examination of a single sample of sputum may not reveal the sensitivity of the prevailing infection, and the recovery of resistant strains would not, therefore, preclude a clinical response to isoniazid.

(2) The variation in sensitivity of cultures grown from consecutive specimens of sputum in three cases suggests that resistant and sensitive foci of infection can exist in different parts of the lung. The result of a sensitivity test may thus depend upon the source of the sputum under examination or the relative access to the bronchi of separate lesions at that particular time. The simultaneous variation in streptomycin and isoniazid sensitivity observed in four cases implies that certain conditions predisposing to the development of resistance within a tuberculous lesion are common to both these drugs.

(3) All of the eight patients showing evidence of a combined infection (five in a single sample of sputum and three in separate samples) had previously yielded highly resistant strains on the cessation of isoniazid treatment, and seven of these have subsequently yielded completely sensitive strains. (The eighth patient has so far been observed for only three months after the withdrawal of isoniazid.) Such evidence of a combined infection has not been found in more than 400 sensitivity tests carried out in the same laboratory before and during isoniazid therapy, nor in those resistant cases which have so far failed to yield sensitive strains. It therefore seems that reversion from a resistant to a predominantly sensitive infection is characterized by sudden changes or by a variability in the sensitivity of the organisms recovered, rather than by a gradual lowering of the degree of their resistance (see Table III). Reversion could thus be explained either by the closure or healing of resistant foci of infection or by the overgrowth of resistant organisms by sensitive mutants. This view would be in keeping with the observation that resistant tubercle bacilli may be less virulent than the sensitive organisms (Mitchison, 1954).

\section{Practical Applications}

Two important practical considerations which arise in relation to isoniazid resistance and reversion to sensitivity are: (1) Should isoniazid ever be given to patients who are yielding resistant strains ? and (2) Is isoniazid of any significant value in patients who have reverted from a resistant to a predominantly sensitive infection?
It has already been mentioned that a clinical response to isoniazid may continue after the first resistant strains have been recovered in the laboratory. On the other hand, we have had disturbing results from giving marsilid to patients who had consistently yielded resistant organisms since their original course of isoniazid. When marsilid first became available (and before it was known that there was crossresistance between it and isoniazid), eight patients with known isoniazid-resistant strains were treated with marsilid for periods of one to three months. None of these showed any significant improvement as judged by $x$-ray changes, blood sedimentation rate, or reduction in the amount or infectivity of the sputum. Three of them actually deteriorated during the first month of marsilid therapy with an increasing amount of sputum and a rising blood sedimentation rate. One of the three (whose condition had shown little change during the preceding nine months) became seriously ill in the third week of treatment with a high fever and radiological extension of the disease. Three separate specimens of sputum from this patient were then tested for isoniazid sensitivity, and it was found that the bacilli from each specimen grew more profusely on the isoniazid media than on the control. The heaviest growth was noted in the medium containing the highest concentration of isoniazid $(50 \mu \mathrm{g}$. per ml.) and the least growth occurred in the drugfree medium. These three patients all improved when marsilid was withdrawn. A fourth patient, whose condition remained unchanged during marsilid therapy, showed some radiological clearing after the drug was withdrawn. Evidence of enhanced growth in the isoniazid media was also noted in this case. (It should be emphasized that the effect of marsilid against sensitive tuberculous infections is of a similar order to that of isoniazid, and a deterioration such as is described above has not been seen among more than 80 sensitive cases treated at the London Hospital.) It has recently been shown that treatment with isoniazid may also increase the virulence of resistant infections in mice (Barnett et al., 1953b) and in guinea-pigs (Mitchison, 1954).

We have as yet little evidence concerning the value of isoniazid in the treatment of patients who have reverted from a resistant to a predominantly sensitive infection. Three of these patients have been given second courses of isoniazid, but the clinical value of the drug was masked by the fact that it was combined with streptomycin and that surgical measures were also adopted. It is of some interest, however, that in each case the bacilli have so far remained sensitive to isoniazid-in two cases after six weeks' treatment, and after four weeks' treatment in the third case.

\section{Summary and Conclusions}

Clinical and bacteriological evidence of cross-resistance between isoniazid and its isopropyl derivative (marsilid) is presented: a tuberculous infection resistant to one was invariably found to be resistant to the other.

A slight degree of isoniazid resistance (growth in $0.2 \mu \mathrm{g}$. per ml.) was detected in $5.6 \%$ of all pre-treatment cultures, but the practical significance of this finding is doubtful. Higher levels of resistance were not found in patients who had not previously received isoniazid.

The results of sensitivity studies in small " pilot" treatment groups of patients with pulmonary tuberculosis are reported. These results indicate that $1 \mathrm{~g}$. of streptomycin given either twice or thrice weekly will not prevent isoniazid resistance over a four-months period, but streptomycin resistance was not observed in either of these two groups. A high incidence of isoniazid (and marsilid) resistance was also noted among patients treated with marsilid alone; but not when this drug was combined with $1 \mathrm{~g}$. of streptomycin three times weekly. 
Of 21 patients yielding isoniazid-resistant strains, 9 $(44.4 \%)$ showed reversion to sensitivity within twelve months of the cessation of treatment. Certain factors which may determine reversion to sensitivity are discussed.

A variability in the sensitivity of different cultures from the same patient and in the clinical response to isoniazid of patients yielding resistant strains is noted. It is suggested that in some cases a combined infection with resistant and sensitive strains may exist and that the examination of a single sample of sputum may not reveal the sensitivity of the prevailing infection.

Certain practical implications of isoniazid resistance and of reversion to sensitivity are discussed. Attention is drawn to the dangers of giving isoniazid or marsilid to patients consistently yielding resistant strains: not only may reversion to sensitivity be delayed, but a dangerous exacerbation of the disease can be induced.

I wish to thank Dr. H. B. May, Dr. Kenneth Perry, Dr. Lloyd Rusby, and Dr. F. C. O. Valentine for their constant encouragement and advice in the preparation of this paper. I am also indebted to $\mathrm{Mr}$. Robert Fewell for his invaluable assistance in carrying out a large number of sensitivity tests, and to Roche Products Limited, who kindly provided the marsilid used in this trial.

\section{REFERENCES}

Barnett. M., Bushby, S. R. M., and Mitchison, D. A. (1953a). Lancet, $1,314$.

- (1953b). Brit. J. exp. Path., 34, 568.

Joiner, C. L. MacL). Lancet, 2, 20. Pard, E. K. Anderson, K., Collard. P., King, M. B., and Knox, R. (1952). Ibid., 2, 843.

Knox, R. (1953). Ibid., 1, 443 .

Medical Research Council (1952). British Medical Journal, 2, 735.

(1953a). Ibid., 1, 521 .

(1953b). Ibid., 2, 1005 .

- (1953c). Lancet, 2, 217 .

Mitchison. D. A. (1954). British Medical Journal, 1, 128.

Nash. J. C.. and Grosfeld, W. (1952). J. Amer, med. Ass, 150, 813

Nigoghossian, G. A. (1953). Schweiz med. Wschr. 83, 218 .

Nitti, V. (1952). Arch. Tisiol., 7. 735 .

Ogilvie, C. M. (1953). Ouart. J. Med, 22511.

Pansy, F. Stander, H., and Donovick, R. (1952). Amer. Rev. Tuberc. 65. 761.

Robitzek, E. H., Selikoff, I. J., Mamlok, E., and Tendlau, A. (1953). Dis. Chest, 23, 1 .

Steenken, W., and Wolinsky, E. (1952). Amer. Rev. Tuberc., 65, 365 United States Public Health Services (1953). Ibid., 67, 553.

\section{SURGICAL INDUCTION OF LABOUR IN MODERN OBSTETRIC PRACTICE*}

BY

\section{R. A. TENNENT, M.B., F.R.F.P.S., F.R.C.O.G.}

\author{
AND
}

\section{D. BLACK, M.B., F.R.F.P.S., F.R.C.S.Ed. F.R.C.O.G.}

Consultant Obstetricians and Gynaecologists, Lanark County Area

The risk of infection has ceased to play a dominating part in the management of obstetric cases since chemotherapeutic and antibiotic substances have shown themselves capable of either preventing or controlling this hazard. This had led to the more frequent employment of obstetric procedures which in the past were thought to predispose to the introduction or spread of infection of the genital tract. Caesarean section and manual removal of the placenta have perhaps been the most notable examples of this trend. There can be little argument that the effect, in regard to the employment

*The paper read by Dr. Tennent in the Section of Obstetrics and Gynaecology at the Annual Meeting of the British Medical Association, Glasgow, 1954, was based on this work. of these two procedures, has been beneficial for both child and mother. In our own practice during the last few years a similar trend has been noted in our employment of surgical induction of labour by artificial rupture of the membranes. This is a well-tried procedure the effects of which have been the subject of many reports in the last twenty years. A report by Gibson (1952) gives a comprehensive survey of the position up to that time.

The main objections to surgical induction of labour in the past have been the risk of infection to mother and child, especially in cases in which the latent period between induction and the onset of labour was prolonged, prejudice against the subsequent conduct of labour, especially with regard to the employment of caesarean section, and the poor chance of survival of a small child when the clinical estimate of foetal size before induction had been inaccurate. Under modern conditions these objections are, in our opinion, less valid, and consequently artificial rupture of the membranes can be employed in a greater variety of conditions than previously. Apart from cases of hypertensive toxaemia, the object in inducing labour should be to promote easy vaginal delivery of a healthy child of reasonable size without detriment to the mother. In hypertensive toxaemia the induction should be carried out either to remove the child from what is considered to be an unhealthy environment or to prevent advancing toxaemia. It is hoped that frequent employment of induction of labour should result in a low foetal mortality and that, in achieving this, resort to caesarean section should be necessary on as few occasions as possible.

A review of the cases in which surgical induction of labour has been performed during the years 1950, 1951, and 1952 in the maternity units at the County of Lanark Maternity Hospital, Bellshill, and the William Smellie Memorial Hospital, Lanark, was therefore undertaken. These cases have all been under our personal control, and we have been responsible for the policy of induction of labour and subsequent management.

During the years mentioned labour was induced by artificial rupture of the membranes in 1,585 cases. : This represents $18.3 \%$ of all deliveries in the hospitals during this period. Thirty-one cases of ante-partum haemorrhage have not been included because of the doubt which exists in these cases whether they are already in labour at the time of induction and because of the difficulty of estimating the effect on the foetus.

\section{Method}

The usual practice was to puncture the amniotic sac with a male metal catheter or with the type of catheter described by Drew Smythe (1931). Either the forewaters or the hindwaters were punctured, the object being to allow the liquor amnii to drain away. In most cases the membranes were separated from the region of the internal os before the puncture was performed. The patient was then allowed to go into labour. Only in occasional cases in which the latent period was prolonged was medical induction given in addition. It was singularly unsuccessful in our hands, but pituitary extract was very seldom used. No regard has been paid to the condition of the cervix. Once the decision was taken to induce labour the membranes were ruptured whether the cervix was taken up or whether it was closed with a long narrow canal. Similarly no regard was paid to whether the head was fixed or free in taking the decision to induce labour.

Indications.-The main indications for induction are shown in Table I. 